\title{
Kajian Jaringan Drainase Kampus UNNES Menuju Sistem Drainase Berwawasan Lingkungan
}

\author{
Bambang Sugiyarto ${ }^{1}$, Suripin², Suharyanto ${ }^{3}$ \\ 1,2,3 Program Magister Teknik Sipil, Departemen Teknik Sipil, Fakultas Teknik, Universitas Diponegoro
}

\section{Kata Kunci/ Keywords :}

Drainage systems, conservation, absorption wells.

sistem drainase, konservasi, sumur resapan

\begin{abstract}
Abstrak:
The new paradigm of the drainage system places urban drainage as a city infrastructure that is grounded in an environmentally oriented or sustainable drainage concept. UNNES campus needs to create a pool / well and absorption well so that rain water falling in the UNNES environment can be accommodated and impregnated into the soil. The purpose of this research is to know the water runoff discharge, the existing drainage capacity and the need of absorption wells as a method of water conservation in UNNES area. Data analysis used in this research is rainfall, average rainfall area, rain type distribution, time of concentration calculation, determination of rainfall intensity at 2, 5, 10, 20 and 50 year rearrangement, division of drainage zone,calculation of flood discharge, calculation of existing channel capacity and calculation of absorbing well needs. The number of recharge wells needed is 1,388 pieces with a depth of 3 meters and a diameter of $80 \mathrm{~cm}$.
\end{abstract}

Paradigma baru sistem drainase menempatkan drainasi perkotaan sebagai prasarana kota yang dilandaskan pada konsep drainase yang berwawasan lingkungan atau berkelanjutan. Kampus UNNES perlu membuat tampungan/embung dan sumur resapan sehingga air hujan yang jatuh di lingkungan UNNES dapat ditampung dan diresapkan ke dalam tanah. Tujuan dari penelitian ini adalah untuk mengetahui debit limpasan air, kapasitas drainase eksisting dan kebutuhan sumur resapan sebagai metode konservasi air di kawasan UNNES. Analisis data yang digunakan dalam penelitian ini adalah curah hujan, curah hujan rata-rata kawasan, pemilihan jenis distribusi hujan, perhitungan waktu konsenstrasi, menentukan besarnya intensitas hujan pada kala ulang 2, 5, 10, 20 dan 50 tahunan, pembagian zona drainase, perhitungan Debit banjir, perhitungan kapasitas saluran eksisting dan penghitungan kebutuhan sumur resapan. Jumlah sumur resapan yang dibutuhkan sebanyak 1.388 buah dengan kedalaman 3 meter dan diameter $80 \mathrm{~cm}$.

Sitasi:

Sugiyarto, Bambang. (2017). Kajian Jaringan Drainase Kampus UNNES Menuju Sistem Drainase Berwawasan Lingkungan. Jurnal Teknik Sipil \& Perencanaan, 19(2), 136-142.

(C) 2017 Universitas Negeri Semarang

\footnotetext{
Bambang Sugiyarto :

Fakultas Teknik, Depatemen Teknik Sipil

E-mail: bambangunnes09@gmail.com
} 


\section{PENDAHULUAN}

Paradigma baru sistem drainase menempatkan drainasi perkotaan sebagai prasarana kota yang dilandaskan pada konsep drainase yang berwawasan lingkungan atau berkelanjutan. Untuk itu perlu diupayakan agar air hujan yang jatuh ditahan terlebih dahulu untuk memperbesar jumlah air yang meresap ke dalam tanah melalui daerah resapan alamiah maupun buatan (Sedyowati L dan Suhartanto E, 2015). Pengembangan konsep drainase berwawasan lingkungan ini diperkuat dengan kebijakan prinsip Zero Delta Q yang terdapat pada Peraturan Pemerintah No 26 Tahun 2008 tentang Rencana Tata Ruang Wilayah Nasional yang diterbitkan tanggal 10 Maret 2008. Pada prinsip Zero Delta Q mengharuskan agar tiap bangunan tidak boleh mengakibatkan bertambahnya debit air ke sistem saluran drainase atau sistem aliran sungai.

Sumiyadi (2016) telah meneliti perubahan tata guna lahan pada kawasan hunian BSB (Bukit Semarang Baru) dengan hasil perubahan tata guna lahan dapat meningkatkan debit limpasan cukup signifikan. Berdasarkan penelitian tersebut, perubahan tata guna lahan di kampus UNNES perlu di analisa sehingga bisa memenuhi kebijakan Pemerintah tentang prinsip Zero Delta Q.

Rekayasa agar tidak ada perubahan debit limpasan dapat dengan cara membuat tampungan/embung dan sumur resapan sehingga air hujan yang jatuh di lingkungan UNNES dapat ditampung dan diresapkan ke dalam tanah. Tujuan dari penelitian ini adalah untuk mengetahui debit limpasan air dan kebutuhan sumur resapan sebagai metode konservasi air di kawasan UNNES.

\section{METODE \\ Lokasi Penelitian dan Analisis yang Dilaksanakan}

Penelitian dilaksanakan di kawasan UNNES yang terletak di Kelurahan Sekaran, Kecamatan Gunungpati, Kota Semarang. UNNES merupakan kawasan yang termasuk dalam wilayah DAS Kali Garang. Wilayah DAS Kali Garang terdiri dari Sub DAS Garang, Sub DAS Kreo dan Sub Das Kripik. Analisis data yang digunakan dalam penelitian ini adalah curah hujan, curah hujan rata-rata kawasan, pemilihan jenis distribusi hujan, perhitungan waktu konsenstrasi, menentukan besarnya intensitas hujan pada kala ulang 2, 5, 10, 20 dan 50 tahunan, pembagian zona drainase, perhitungan Debit banjir, perhitungan kapasitas saluran eksisting dan penghitungan kebutuhan sumur resapan.

\section{Data yang Digunakan}

Untuk menunjang penelitian, dibutuhkan data yang berupa data primer dan sekunder. Data Sekunder meliputi :
1. Data Curah Hujan selama 15 tahun terakhir, yang didapatkan dari BMKG.

2. Peta Topografi dan Peta situasi, didapatkan dari Universitas Negeri Semarang

3. Peta Jaringan Drainase UNNES.

Sedangkan Data Primer meliputi :

1. Survai elevasi dasar saluran dan kemiringan saluran

Survai elevasi dasar saluran bertujuan untuk mengetahui kemiringan saluran sehingga nantinya dapat digunakan untuk menghitung hidraulika saluran.

2. Survai panjang saluran, bentuk saluran dan material saluran

Survai ini bertujuan untuk menentukan koefisien manning saluran untuk perhitungan hidraulika saluran.

\section{HASIL PEMBAHASAN \\ Daerah Penelitian}

Universitas Negeri Semarang (UNNES) merupakan salah satu perguruan tinggi negeri di Indonesia yang mencetak tenaga ahli dibidang pendidikan dan non kependidikan. Unnes dikenal sebagai Universitas Konservasi dan diperkuat setelah ada pengukuhan dari Menteri Pendidikan Nasional pada tanggal 12 Maret 2010.

Kampus utama UNNES terletak di daerah Sekaran, Kecamatan Gunungpati, Kota Semarang. Kampus Unnes di Sekaran, merupakan kepindahan Kampus Unnes (dahulu IKIP Semarang) di Jalan Kelud Semarang No.2 Kota Semarang. Kepindahan ini dilakukan pertama kali pada tahun 1991.

Perkembangan pembangunan UNNES belakangan ini terus meningkat dengan dibangunnya beberapa bangunan gedung bertingkat dan perluasan jalan. Tujuan pembangunan ini adalah untuk meningkatkan fasilitas sarana prasarana di UNNES sehingga para mahasiswa dapat lebih nyaman dan efektif dalam kegiatan belajar di kampus. Tetapi proses pembangunan yang pesat ini mengakibatkan perubahan tata guna lahan yang mulanya merupakan lahan terbuka hijau menjadi lahan terbangun. Perubahan tata guna lahan ini mengakibatkan berkurangnya fungsi lahan sebagai resapan air sehingga debit limpasan air pada saluran drainase di lingkungan UNNES menjadi meningkat.

\section{Penentuan Batas Sub DAS Unnes}

Kawasan Unnes Sekaran terletak pada DAS Garang. Daerah aliran sungai (DAS) Garang merupakan DAS yang terletak di Provinsi Jawah Tengah. DAS Garang terdiri dari tiga sungai yaitu Kali Kripik, Kali Kreo dan Kali Garang, berhulu di Kecamatan Ungaran Kabupaten Semarang dan 
bermuara di Laut Jawa (Kota Semarang). DAS Garang secara administrasi masuk wilayah Kabupaten Semarang, Kota Semarang dan Kabupaten Kendal. DAS Garang memiliki luas 209,32 km², sedangkan DAS Kawasan UNNES memiliki luas $2,451 \mathrm{~km}^{2}$.

\section{Hujan Rencana}

Hujan rencana didapatkan dengan cara melakukan analisa hujan kawasan terhadap data hujan selama 15 tahun dan selanjutnya ditentukan jenis distribusi datanya. Penentuan jenis ditribusi hujan menggunakan software Analisis Frekuensi Data Hidrologi (AProb_4.1) yang dikembangkan oleh Istiarto (2014). Chow et al. (1988), Haan (1982), Sri Harto (2000) serta Togani dan Kusumawardani (2016) mengusulkan prosedur pengujian dan menentukan jenis distribusi dengan uji chi kuadrat dan smirnov kolmogorov. Berdasarkan hasil pengujian data hujan diketahui bahwa distribusi yang cocok adalah ditribusi Log Normal. Menurut Triatmodjo, B (2008), bentuk fungsi distribusi kontinyu (teoritis), yang sering digunakan dalam analisis frekuensi Log Normal, adalah:

$\mathrm{YT}=\overline{\mathrm{Y}}+\mathrm{K}_{\mathrm{T}}$

dengan :

YT = perkiraan nilai yang diharapkan terjadi dengan periode ulang T-tahunan,

$\overline{\mathrm{Y}} \quad=$ nilai rata-rata hitung variat,

$\mathrm{S} \quad=$ deviasi standar nilai variat,

$\mathrm{KT} \quad=$ faktor frekuensi, merupakan fungsi dari peluang atau periode ulang dan tipe model matematik distribusi peluang yang digunakan untuk analisis peluang

Hasil Perhitungan hujan rencana dengan menggunakan distribusi Log Normal, dengan nilai :

Rata-rata $\quad=113,5241$

Standar Deviasi $=36,5575$

Tabel 1 Hitungan Hujan Rencana dengan Distribusi Log Normal

\begin{tabular}{cc}
\hline $\begin{array}{c}\text { Periode Ulang } \\
\text { (th) }\end{array}$ & $\begin{array}{c}\text { Hujan Rencana } \\
\text { (mm) }\end{array}$ \\
\hline 2 & 107,96 \\
5 & 142,87 \\
10 & 165,41 \\
20 & 186,68 \\
50 & 213,90 \\
\hline
\end{tabular}

\section{Zona Drainase UNNES}

Zona drainase di kawasan UNNES Sekaran dibagi menjadi 28 zona, pembagian zona ini didasarkan pada kondisi lapangan yang disebabkab oleh adanya saluran drainase dan jalan. Pembagian zona drainase ditunjukkan pada gambar 1 dan luasan masing-masing zona ditunjukkan pada tabel 2.

Pada zona A dan Zona B aliran air dibuang ke arah Barat yaitu ke kali Kripik. Zona D akan mengalir kearah timur dan mengarah ke embung. Zona $\mathrm{C}$ akan mengalir dan bertemu dengan saluran di zona $\mathrm{H}$. Zona $\mathrm{G}$ akan mengalir kearah timur dan bertemu dengan aliran dari zona $F$, yang selanjutnya akan berbertemu dengan Zona $\mathrm{K}$, Selanjutnya akan bertemu dengan gabungan zona $\mathrm{C}$ dan $\mathrm{H}$, kemudian akan menuju ke Embung. Selanjutnya dari embung air akan mengalir ke arah kali Kedung Kidang.

Zona $\mathrm{J}$ akan mengalir kearah timur dan selanjutnya mengarah ke kali Kedung Kidang. Zona $\mathrm{E}$ akan mengarah ke Timur dan bertemu dengan aliran dari Zona I, yang selanjutnya akan mengalir ke kali Kedung Kidang. Zona M dan Zona O akan langsung mengalir ke kali Kedung Kidang, demikian pula dengan Zona $\mathrm{N}$ dan Zona $\mathrm{Q}$. Zona $\mathrm{P}$ akan mengalir kearah barat, yang selanjutnya akan mengalir ke kali Kedung Kidang. Sedangkan Zona $\mathrm{R}$, akan mengalir kearah timur menuju ke anak kali Garang.

Zona S dan Zona dan Zona T, akan mengalir ke timur dan mengarah ke Anak Kali Garang. Zona $\mathrm{U}$ dan Zona dan Zona $\mathrm{V}$, akan mengalir ke barat dan mengarah ke Anak Kali Garang. Sedangkan Zona $Y$ akan mengalir menjadi aliran liar. Zona $W$ dan Zona dan Zona Z, akan mengalir ke barat dan mengarah ke Anak Kali Garang. Zona AA mengalir kearah barat menuju ke anak Kali Garang, sedangkan Zona $A B$ akan mengalir menjadi aliran liar.

Tabel 2. Luas Zona dan Koefisien Limpasan Gabungan Zona Drainase UNNES

\begin{tabular}{ccc}
\hline Zona & $\begin{array}{c}\text { Luas } \\
(\mathrm{Ha})\end{array}$ & $\begin{array}{c}\text { Koefisien } \\
\text { Limpasan } \\
\text { Gabungan }\end{array}$ \\
\hline Zona A & 2,83 & 0,2540 \\
Zona AA & 2,45 & 0,5540 \\
Zona AB & 1,96 & 0,5623 \\
Zona B & 1,67 & 0,5704 \\
Zona C & 2,13 & 0,4097 \\
Zona D & 6,38 & 0,5487 \\
Zona E & 1,60 & 0,2762 \\
Zona F & 4,14 & 0,5293 \\
Zona G & 2,10 & 0,3279 \\
Zona H & 2,89 & 0,4484 \\
Zona I & 3,07 & 0,6095 \\
Zona J & 1,41 & 0,4629 \\
Zona K & 1,08 & 0,4139 \\
Zona L & 0,52 & 0,3334 \\
Zona M & 0,27 & 0,6261 \\
Zona N & 0,31 & 0,6911 \\
Zona O & 0,35 & 0,5084 \\
Zona P & 1,65 & 0,5903 \\
\hline
\end{tabular}




\begin{tabular}{ccc}
\hline Zona & $\begin{array}{c}\text { Luas } \\
(\mathrm{Ha})\end{array}$ & $\begin{array}{c}\text { Koefisien } \\
\text { Limpasan } \\
\text { Gabungan }\end{array}$ \\
\hline Zona Q & 3,14 & 0,5855 \\
Zona R & 3,21 & 0,5792 \\
Zona S & 2,17 & 0,3005 \\
Zona T & 0,86 & 0,2000 \\
Zona U & 3,76 & 0,4549 \\
Zona V & 4,65 & 0,3050 \\
\hline
\end{tabular}

\begin{tabular}{ccc}
\hline Zona & $\begin{array}{c}\text { Luas } \\
(\mathrm{Ha})\end{array}$ & $\begin{array}{c}\text { Koefisien } \\
\text { Limpasan } \\
\text { Gabungan }\end{array}$ \\
\hline Zona W & 2,72 & 0,6362 \\
Zona X & 1,49 & 0,2139 \\
Zona Y & 2,01 & 0,3402 \\
Zona Z & 1,58 & 0,5683 \\
Jumlah & 62,41 & 0,4263 \\
\hline
\end{tabular}

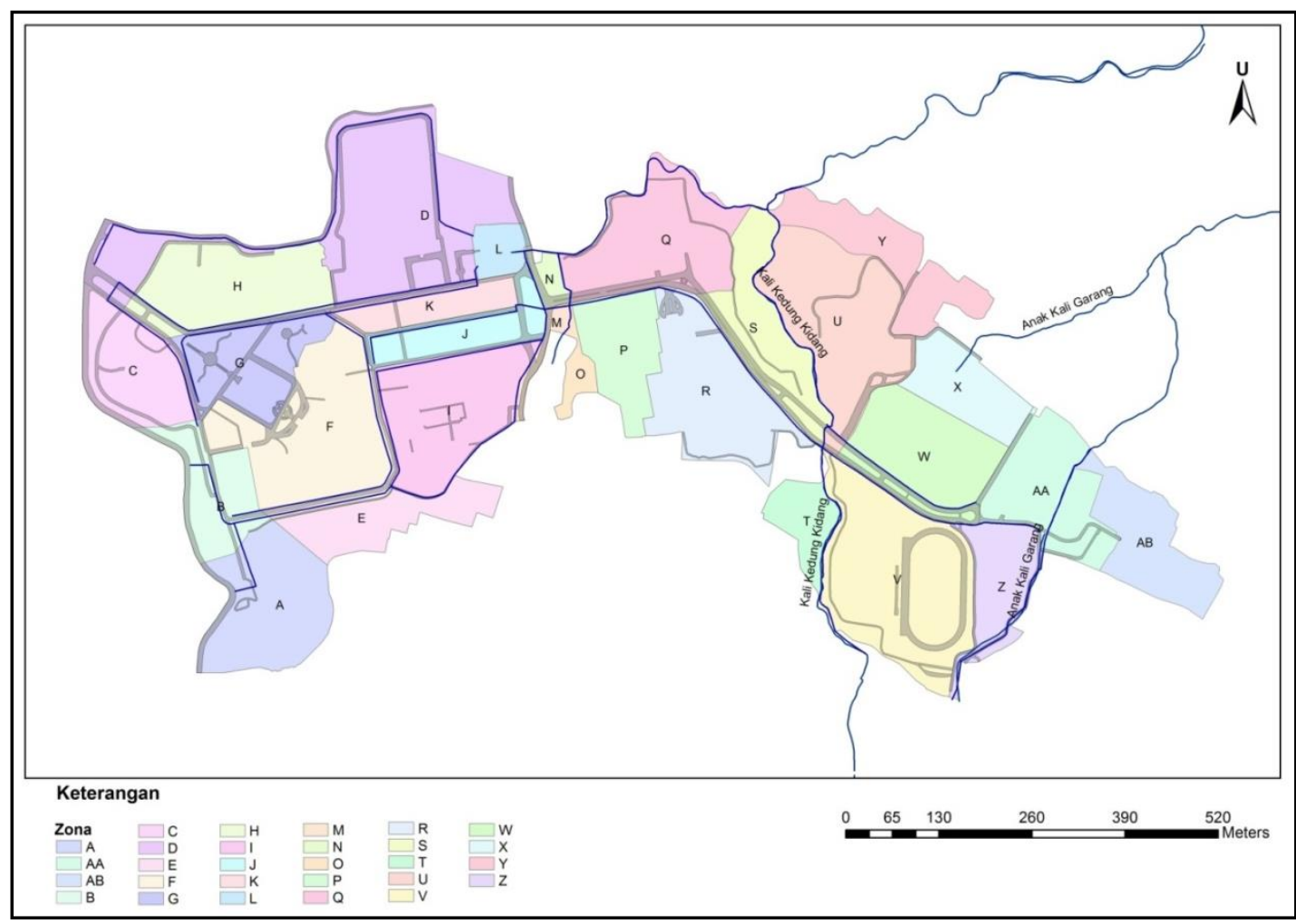

Gambar 1 . Pembagian Zona Drainase Kawasan UNNES

\section{Debit Puncak Pada Masing-Masing Zona}

Analisis debit puncak dilakukan dengan menggunakan Metode Rasional (Suripin, 2004),

$Q \quad=0,002778 \times C \times I \times A$

dengan :
$\mathrm{Q}=$ debit maksimum (m3/dt)
$\mathrm{C}=$ koefisien limpasan
$\mathrm{I}=$ Intensitas curah hujan rata-rata $(\mathrm{mm} / \mathrm{jam})$

$\mathrm{A}=$ luas daerah pengaliran $(\mathrm{Ha})$

Pada masing-masing zona, dengan menggunakan hasil analisa Tabel 1 dan data intensitas hujan tiap zona. Hasil perhitungan debit puncak pada masing-masing Zona, sebelum dan Setelah pengembangan UNNES dapat dilihat pada Tabel 3.

Tabel 3. Perbandingan Debit Puncak pada Masing-Masing Zona (Sebelum dan Setelah Pengembangan UNNES)

\begin{tabular}{|c|c|c|c|c|c|c|c|c|c|c|c|c|c|c|c|}
\hline \multirow{3}{*}{ Zona } & \multirow{3}{*}{$\begin{array}{l}\text { Luas } \\
(\mathrm{Ha})\end{array}$} & \multicolumn{6}{|c|}{ Sebelum Pengembangan UNNES } & \multicolumn{6}{|c|}{ Setelah Pengembangan UNNES } & \multirow{2}{*}{\multicolumn{2}{|c|}{$\begin{array}{l}\text { Peningkatan } \\
\text { Debit Pada } \\
\text { Periode Ulang } \\
10 \text { Tahun }\end{array}$}} \\
\hline & & \multirow{2}{*}{$\begin{array}{l}\text { Koef. } \\
\text { Limpasan } \\
\text { (C) }\end{array}$} & \multicolumn{5}{|c|}{$\begin{array}{l}\text { Debit Puncak } \\
\left.\text { ( } \mathrm{m}^{3} / \text { detik }\right)\end{array}$} & \multirow{2}{*}{$\begin{array}{l}\text { Koefisien } \\
\text { Limpasan } \\
\text { (C) }\end{array}$} & \multicolumn{5}{|c|}{$\begin{array}{l}\text { Debit Puncak } \\
\text { (m³/detik) }\end{array}$} & & \\
\hline & & & 2 & 5 & 10 & 20 & 50 & & 2 & 5 & 10 & 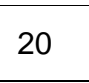 & 0 & $\begin{array}{l}\Delta \text { Debit } \\
(\mathrm{m} 3 / \mathrm{dt})\end{array}$ & $\%$ \\
\hline & & & & & & & & & & & & & & 0,17 & $27^{\circ}$ \\
\hline Zona $\mathrm{AA}$ & 2,45 & 0,20 & 0,44 & 0,59 & 0,68 & 0,77 & 0,88 & 0,5542 & 1,23 & 1,63 & 1,88 & 2,13 & 2,44 & 1,20 & $177^{\circ}$ \\
\hline
\end{tabular}




$\begin{array}{cccccccc}\text { Zona AB } & 1,96 & 0,20 & 0,21 & 0,28 & 0,32 & 0,36 & 0,41 \\ \text { Zona B } & 1,67 & 0,20 & 0,18 & 0,24 & 0,27 & 0,31 & 0,35 \\ \text { Zona C } & 2,13 & 0,20 & 0,20 & 0,26 & 0,30 & 0,34 & 0,39 \\ \text { Zona D } & 6,38 & 0,20 & 0,28 & 0,37 & 0,43 & 0,48 & 0,55 \\ \text { Zona E } & 1,60 & 0,20 & 0,11 & 0,15 & 0,17 & 0,19 & 0,22 \\ \text { Zona F } & 4,14 & 0,20 & 0,27 & 0,36 & 0,42 & 0,47 & 0,54 \\ \text { Zona G } & 2,10 & 0,20 & 0,19 & 0,25 & 0,29 & 0,33 & 0,37 \\ \text { Zona H } & 2,89 & 0,20 & 0,17 & 0,23 & 0,26 & 0,30 & 0,34 \\ \text { Zona I } & 3,07 & 0,20 & 0,25 & 0,33 & 0,38 & 0,43 & 0,49 \\ \text { Zona J } & 1,41 & 0,20 & 0,10 & 0,13 & 0,15 & 0,17 & 0,20 \\ \text { Zona K } & 1,08 & 0,20 & 0,11 & 0,14 & 0,16 & 0,19 & 0,21 \\ \text { Zona L } & 0,52 & 0,20 & 0,09 & 0,12 & 0,13 & 0,15 & 0,17 \\ \text { Zona M } & 0,27 & 0,20 & 0,04 & 0,06 & 0,07 & 0,08 & 0,09 \\ \text { Zona N } & 0,31 & 0,20 & 0,08 & 0,10 & 0,12 & 0,13 & 0,15 \\ \text { Zona O } & 0,35 & 0,20 & 0,06 & 0,08 & 0,09 & 0,10 & 0,12 \\ \text { Zona P } & 1,65 & 0,20 & 0,25 & 0,34 & 0,39 & 0,44 & 0,50 \\ \text { Zona Q } & 3,14 & 0,20 & 0,31 & 0,41 & 0,47 & 0,53 & 0,61 \\ \text { Zona R } & 3,21 & 0,20 & 0,25 & 0,33 & 0,39 & 0,44 & 0,50 \\ \text { Zona S } & 2,17 & 0,20 & 0,24 & 0,31 & 0,36 & 0,41 & 0,47 \\ \text { Zona T } & 0,86 & 0,20 & 0,08 & 0,10 & 0,12 & 0,13 & 0,15 \\ \text { Zona U } & 3,76 & 0,20 & 0,41 & 0,54 & 0,63 & 0,71 & 0,81 \\ \text { Zona V } & 4,65 & 0,20 & 0,42 & 0,56 & 0,64 & 0,73 & 0,83 \\ \text { Zona W } & 2,72 & 0,20 & 0,28 & 0,37 & 0,42 & 0,48 & 0,55 \\ \text { Zona X } & 1,49 & 0,20 & 0,34 & 0,45 & 0,52 & 0,59 & 0,68 \\ \text { Zona Y } & 2,01 & 0,20 & 0,18 & 0,24 & 0,28 & 0,31 & 0,36 \\ \text { Zona Z } & 1,58 & 0,20 & 0,14 & 0,19 & 0,22 & 0,25 & 0,28\end{array}$

Debit Atap pada masing-masing zona

Analisa dilakukan dengan mengasumsikan bahwa seluruh hujan yang ada akan ditampung pada sumur resapan, dengan demikian nilai Koefisian atap (C atap) dianggap nol, yang dalam perhitungan selanjutnya diistilahkan Debit Tanpa Atap. Hasil perhitungan Debit tanpa atap, merupakan Debit yang direduksi oleh Sumur Resapan. Perbedaan atau selisih antara Debit dengan atap dan Debit tanpa atap merupakan Debit yang akan digunakan untuk menghitung Sumur Resapan. Hasil perhitungan Debit atap pada masing-masing zona disajikan pada tabel 4 berikut ini.

Tabel 4 . Debit Atap pada Tiap Zona

\begin{tabular}{|c|c|c|c|c|c|c|}
\hline \multirow[t]{2}{*}{ Zona } & \multirow{2}{*}{$\begin{array}{l}\text { Luas } \\
\text { Atap } \\
\text { (Ha) }\end{array}$} & \multicolumn{5}{|c|}{$\begin{array}{l}\text { Debit Atap } \\
\text { (m³/dt) }\end{array}$} \\
\hline & & 2 & 5 & 10 & 20 & 50 \\
\hline Zona A & 0,02 & 0,01 & 0,02 & 0,02 & 0,03 & 0,03 \\
\hline Zona AA & 0,67 & 0,55 & 0,75 & 0,89 & 1,02 & 1,19 \\
\hline Zona AB & 0,64 & 0,31 & 0,43 & 0,50 & 0,58 & 0,67 \\
\hline Zona B & 0,39 & 0,19 & 0,26 & 0,30 & 0,35 & 0,41 \\
\hline Zona C & 0,18 & 0,08 & 0,11 & 0,13 & 0,14 & 0,17 \\
\hline Zona D & 1,40 & 0,28 & 0,38 & 0,45 & 0,51 & 0,60 \\
\hline Zona E & 0,14 & 0,04 & 0,06 & 0,07 & 0,08 & 0,10 \\
\hline Zona F & 0,95 & 0,28 & 0,39 & 0,46 & 0,53 & 0,62 \\
\hline Zona G & 0,00 & 0,00 & 0,00 & 0,00 & 0,00 & 0,00 \\
\hline Zona H & 0,44 & 0,20 & 0,28 & 0,33 & 0,38 & 0,44 \\
\hline Zona I & 1,01 & 0,37 & 0,51 & 0,60 & 0,69 & 0,81 \\
\hline Zona J & 0,10 & 0,03 & 0,04 & 0,05 & 0,06 & 0,07 \\
\hline Zona K & 0,05 & 0,02 & 0,03 & 0,04 & 0,04 & 0,05 \\
\hline Zona L & 0,01 & 0,00 & 0,01 & 0,01 & 0,01 & 0,01 \\
\hline
\end{tabular}

\begin{tabular}{|c|c|c|c|c|c|c|c|}
\hline 5623 & 0,59 & 0,78 & 0,90 & 1,02 & 1,17 & 0,58 & $181 \%$ \\
\hline 0,5704 & 0,51 & 0,67 & 0,78 & 0,88 & 1,00 & 0,50 & $185 \%$ \\
\hline 0,4097 & 0,41 & 0,54 & 0,62 & 0,70 & 0,80 & 0,32 & $105 \%$ \\
\hline 0,5532 & 0,77 & 1,02 & 1,18 & 1,33 & 1,53 & 0,75 & $177 \%$ \\
\hline 0,2762 & 0,15 & 0,20 & 0,23 & 0,26 & 0,30 & 0,06 & $38 \%$ \\
\hline 0,5303 & 0,73 & 0,96 & 1,11 & 1,26 & 1,44 & 0,69 & $165 \%$ \\
\hline 0,3669 & 0,35 & 0,46 & 0,53 & 0,60 & 0,69 & 0,24 & $83 \%$ \\
\hline 0,4501 & 0,39 & 0,51 & 0,59 & 0,67 & 0,76 & 0,33 & $125 \%$ \\
\hline 0,6099 & 0,76 & 1,00 & 1,16 & 1,31 & 1,50 & 0,78 & $205 \%$ \\
\hline 0,4703 & 0,23 & 0,31 & 0,36 & 0,40 & 0,46 & 0,21 & $135 \%$ \\
\hline 0,4139 & 0,22 & 0,29 & 0,34 & 0,38 & 0,44 & 0,18 & $107 \%$ \\
\hline 0,3334 & 0,15 & 0,19 & 0,22 & 0,25 & 0,29 & 0,09 & $67 \%$ \\
\hline 0,6281 & 0,14 & 0,18 & 0,21 & 0,24 & 0,28 & 0,15 & $214 \%$ \\
\hline 0,6924 & 0,26 & 0,35 & 0,40 & 0,46 & 0,52 & 0,29 & $246 \%$ \\
\hline 0,5084 & 0,15 & 0,20 & 0,23 & 0,26 & 0,29 & 0,14 & $154 \%$ \\
\hline 0,5929 & 0,75 & 1,00 & 1,16 & 1,30 & 1,49 & 0,77 & $196 \%$ \\
\hline 0,5860 & 0,90 & 1,19 & 1,38 & 1,56 & 1,78 & 0,91 & $193 \%$ \\
\hline 0,5866 & 0,74 & 0,98 & 1,14 & 1,28 & 1,47 & 0,75 & $193 \%$ \\
\hline 0,3037 & 0,36 & 0,48 & 0,55 & 0,62 & 0,71 & 0,19 & $52 \%$ \\
\hline 0,2000 & 0,08 & 0,10 & 0,12 & 0,13 & 0,15 & 0,00 & $0 \%$ \\
\hline 0,4572 & 0,94 & 1,24 & 1,44 & 1,63 & 1,86 & 0,81 & $129 \%$ \\
\hline 0,3363 & 0,71 & 0,93 & 1,08 & 1,22 & 1,40 & 0,44 & $68 \%$ \\
\hline 0,6404 & 0,89 & 1,17 & 1,36 & 1,54 & 1,76 & 0,94 & $220 \%$ \\
\hline 0,2590 & 0,44 & 0,58 & 0,68 & 0,76 & 0,88 & 0,15 & $30 \%$ \\
\hline 0,3410 & 0,31 & 0,41 & 0,47 & 0,53 & 0,61 & 0,19 & $71 \%$ \\
\hline 84 & 0,40 & 0,53 & 0,62 & 0,70 & 0,80 & 0,40 & $184 \%$ \\
\hline \multirow{2}{*}{\multicolumn{2}{|c|}{ Zona }} & $\begin{array}{l}\text { Luas } \\
\text { Atap }\end{array}$ & \multicolumn{5}{|c|}{$\begin{array}{c}\text { Debit Atap } \\
\left(\mathrm{m}^{3} / \mathrm{dt}\right)\end{array}$} \\
\hline & & (Ha) & 2 & 5 & 10 & 20 & 50 \\
\hline \multicolumn{2}{|c|}{ Zona M } & 0,01 & 0,01 & 0,01 & 0,01 & 0,01 & 0,01 \\
\hline \multicolumn{2}{|c|}{ Zona N } & 0,03 & 0,04 & 0,05 & 0,06 & 0,07 & 0,08 \\
\hline \multicolumn{2}{|c|}{ Zona O } & 0,09 & 0,07 & 0,10 & 0,12 & 0,13 & 0,15 \\
\hline \multicolumn{2}{|c|}{ Zona P } & 0,49 & 0,34 & 0,47 & 0,56 & 0,64 & 0,74 \\
\hline \multicolumn{2}{|c|}{ Zona Q } & 0,83 & 0,37 & 0,50 & 0,60 & 0,68 & 0,80 \\
\hline \multicolumn{2}{|c|}{ Zona R } & 0,98 & 0,35 & 0,48 & 0,57 & 0,65 & 0,76 \\
\hline \multicolumn{2}{|c|}{ Zona S } & 0,00 & 0,00 & 0,00 & 0,00 & 0,00 & 0,00 \\
\hline \multicolumn{2}{|c|}{ Zona T } & 0,00 & 0,00 & 0,00 & 0,00 & 0,00 & 0,00 \\
\hline \multicolumn{2}{|c|}{ Zona U } & 0,72 & 0,35 & 0,49 & 0,57 & 0,66 & 0,77 \\
\hline \multicolumn{2}{|c|}{ Zona V } & 0,03 & 0,01 & 0,02 & 0,02 & 0,03 & 0,03 \\
\hline \multicolumn{2}{|c|}{ Zona W } & 0,70 & 0,32 & 0,44 & 0,52 & 0,60 & 0,70 \\
\hline \multicolumn{2}{|c|}{ Zona X } & 0,00 & 0,00 & 0,00 & 0,00 & 0,00 & 0,00 \\
\hline \multirow{2}{*}{\multicolumn{2}{|c|}{$\begin{array}{l}\text { Zona Y } \\
\text { Zona Z }\end{array}$}} & 0,32 & 0,13 & 0,18 & 0,21 & 0,24 & 0,28 \\
\hline & & 0,26 & 0,11 & 0,15 & 0,17 & 0,20 & 0,23 \\
\hline
\end{tabular}

\section{Kebutuhan Sumur Resapan}

Sumur resapan merupakan salah satu metode konservasi air yang cukup efektif terutama di wilayah hulu. Pada metode sumur resapan ini air di resapkan kedalam tanah sehingga limpasan dapat dikurangi.

Secara teoritis volume dan efisiensi sumur resapan dapat dihitung berdasarkan keseimbangan air yang masuk ke sumur dan air yang meresap ke dalam tanah (Sunjoto, 2009) dapat ditulis sebagai berikut:

$$
\mathrm{H}=\frac{\mathrm{Q}}{\mathrm{F} . \mathrm{K}}\left\{1-\exp ^{\left\{\frac{-\mathrm{F} . \mathrm{K} . \mathrm{T}}{\pi \cdot \mathrm{R}^{2}}\right\}}\right\}
$$


dengan :

$$
\begin{aligned}
& \mathrm{H}=\text { kedalaman efektif sumur resapan }(\mathrm{m}), \\
& \mathrm{F}=\text { faktor geometrik, } \\
& \mathrm{Q}=\text { debit air masuk (m3/dt) } \\
& \mathrm{T}=\text { waktu pengaliran (menit), } \\
& \mathrm{K}=\text { koefisien permeabilitas }(\mathrm{m} / \mathrm{dt}), \\
& \mathrm{R}=\text { jari-jari sumur }(\mathrm{m}),
\end{aligned}
$$

Dalam analisis kebutuhan sumur resapan, dimensi sumur dipilih 0,8 $\mathrm{m}$ sehingga nilai jari-jari sumur $(R)=0,4 \mathrm{~m}$ dan kedalaman sumur $3 \mathrm{~m}$. Penentuan nilai faktor geometrik sumur $(F)=5,5 R$ (Sunjoto, 2005), T adalah waktu pengaliran diasumsikan sebagai waktu konsentrasi pada masing-masing zona. Dengan kondisi tanah di UNNES berupa tanah lempung padu padas bercampur batuan dan pasir, maka tanah di kawasan UNNES dikategorikan pada tanah dengan permiabilitas rendah. Sesuai dengan harga

\begin{tabular}{|c|c|c|c|c|c|c|c|c|c|c|}
\hline Zona & $\begin{array}{l}\text { Luas } \\
\text { Atap } \\
(\mathrm{Ha})\end{array}$ & $\begin{array}{c}\text { Debit } \\
\text { Atap } \\
Q \\
\left(\mathrm{~m}^{3} / \mathbf{d t}\right)\end{array}$ & $\begin{array}{c}\text { Waktu } \\
\text { Konsentrasi } \\
T \\
\text { (dt) }\end{array}$ & $\begin{array}{c}\text { Jari2 } \\
\text { Sumur } \\
\text { R } \\
(\mathrm{m})\end{array}$ & $\begin{array}{l}\text { Permea- } \\
\text { bilitas } \\
\text { K } \\
\text { (m/detik) }\end{array}$ & $\begin{array}{c}\text { Faktor } \\
\text { Geomatrik } \\
\text { F } \\
5,5\end{array}$ & $\mathbf{H}$ & $\begin{array}{c}\text { Tinggi } \\
\text { Sumur } \\
\text { Rencana } \\
\text { H } \\
\text { (m) }\end{array}$ & $\begin{array}{l}\text { Jumlah } \\
\text { Sumur }\end{array}$ & $\begin{array}{c}\text { Debit yang } \\
\text { mampu } \\
\text { ditampung } \\
\text { Sumur } \\
\text { Resapan } \\
\text { m }^{3} / \mathrm{dt}\end{array}$ \\
\hline Zona A & 0,02 & 0,02 & 198 & 0,4 & $1,5, \mathrm{E}-04$ & 2,2 & 6,77 & 3 & 3 & 0,02 \\
\hline Zona AA & 0,67 & 0,72 & 140 & 0,4 & 1,5,E-04 & 2,2 & 192,48 & 3 & 65 & 0,73 \\
\hline Zona AB & 0,64 & 0,41 & 310 & 0,4 & $1,5, E-04$ & 2,2 & 228,01 & 3 & 77 & 0,41 \\
\hline Zona B & 0,39 & 0,25 & 310 & 0,4 & $1,5, \mathrm{E}-04$ & 2,2 & 137,53 & 3 & 46 & 0,25 \\
\hline Zona C & 0,18 & 0,10 & 381 & 0,4 & $1,5, \mathrm{E}-04$ & 2,2 & 68,26 & 3 & 23 & 0,10 \\
\hline Zona D & 1,40 & 0,37 & 1.180 & 0,4 & 1,5,E-04 & 2,2 & 596,67 & 3 & 199 & 0,37 \\
\hline Zona E & 0,14 & 0,06 & 601 & 0,4 & 1,5,E-04 & 2,2 & 57,96 & 3 & 20 & 0,06 \\
\hline Zona F & 0,95 & 0,37 & 632 & 0,4 & $1,5, \mathrm{E}-04$ & 2,2 & 385,20 & 3 & 129 & 0,38 \\
\hline Zona G & 0,00 & 0,00 & 402 & 0,4 & 1,5,E-04 & 2,2 & 1,23 & 3 & 1 & 0,00 \\
\hline Zona H & 0,44 & 0,27 & 746 & 0,4 & 1,5,E-04 & 2,2 & 317,07 & 3 & 106 & 0,27 \\
\hline Zona I & 1,01 & 0,49 & 467 & 0,4 & 1,5,E-04 & 2,2 & 392,25 & 3 & 131 & 0,49 \\
\hline Zona J & 0,10 & 0,04 & 580 & 0,4 & $1,5, \mathrm{E}-04$ & 2,2 & 38,53 & 3 & 13 & 0,04 \\
\hline Zona K & 0,05 & 0,03 & 344 & 0,4 & $1,5, \mathrm{E}-04$ & 2,2 & 18,54 & 3 & 7 & 0,03 \\
\hline Zona L & 0,01 & 0,01 & 159 & 0,4 & $1,5, \mathrm{E}-04$ & 2,2 & 1,98 & 3 & 1 & 0,01 \\
\hline Zona M & 0,01 & 0,01 & 159 & 0,4 & $1,5, E-04$ & 2,2 & 2,66 & 3 & 1 & 0,01 \\
\hline Zona N & 0,03 & 0,05 & 87 & 0,4 & $1,5, E-04$ & 2,2 & 8,52 & 3 & 3 & 0,05 \\
\hline Zona O & 0,09 & 0,09 & 159 & 0,4 & 1,5,E-04 & 2,2 & 28,27 & 3 & 10 & 0,10 \\
\hline Zona P & 0,49 & 0,45 & 179 & 0,4 & 1,5,E-04 & 2,2 & 151,77 & 3 & 51 & 0,46 \\
\hline Zona Q & 0,83 & 0,48 & 353 & 0,4 & 1,5,E-04 & 2,2 & 303,22 & 3 & 102 & 0,49 \\
\hline Zona R & 0,98 & 0,46 & 489 & 0,4 & 1,5,E-04 & 2,2 & 382,87 & 3 & 128 & 0,46 \\
\hline Zona S & 0,00 & 0,00 & 299 & 0,4 & $1,5, \mathrm{E}-04$ & 2,2 & 0,00 & 3 & 0 & 0,00 \\
\hline Zona T & 0,00 & 0,00 & 299 & 0,4 & $1,5, \mathrm{E}-04$ & 2,2 & 0,00 & 3 & 0 & 0,00 \\
\hline Zona U & 0,72 & 0,47 & 398 & 0,4 & $1,5, E-04$ & 2,2 & 325,49 & 3 & 109 & 0,47 \\
\hline Zona V & 0,03 & 0,02 & 398 & 0,4 & 1,5,E-04 & 2,2 & 12,43 & 3 & 5 & 0,02 \\
\hline Zona W & 0,70 & 0,43 & 332 & 0,4 & 1,5,E-04 & 2,2 & 253,07 & 3 & 85 & 0,43 \\
\hline Zona X & 0,00 & 0,00 & 99 & 0,4 & 1,5,E-04 & 2,2 & 0,00 & 3 & 0 & 0,00 \\
\hline Zona Y & 0,32 & 0,17 & 402 & 0,4 & 1,5,E-04 & 2,2 & 119,20 & 3 & 40 & 0,17 \\
\hline Zona Z & 0,26 & 0,14 & 402 & 0,4 & 1,5,E-04 & 2,2 & 98,32 & 3 & 33 & 0,14 \\
\hline Jumlah & 10,49 & 5,90 & & & & & & & 1.388 & 5,97 \\
\hline
\end{tabular}
$\mathrm{k}$ untuk jenis-jenis tanah, maka di ditetapkan nilai permeabilitas di kampus UNNES sebesar 0,00015 $\mathrm{cm} /$ detik. Kebutuhan sumur resapan di kampus UNNES dapat dilihat pada tabel berikut ini :

Tabel 5. Kebutuhan Sumur Resapan di Kampus UNNES pada Tiap Zona 
Dari hasil analisis tersebut, diketahui bahwa dari luas atap sebesar 10,49 Ha dibutuhkan sumur sebanyak 1.388 buah. Dari sebanyak 1.388 buah, mampu mereduksi debit sebesar 5,97 m3/dt.

\section{KESIMPULAN}

Berdasarkan analisis data dan pembahasan pada penelitian ini dapat disimpulkan sebagai berikut :

(1) Tata Guna Lahan UNNES sebelum pengembangan berupa tegalan dengan demikian koefisien limpasan diperkirakan sebesar 0,2 . Setelah adanya pengembangan UNNES, Tata Guna Lahan di UNNES berubah dan umumnya terdiri dari bangunan, embung, jalan, lapangan, pekarangan, ruang terbuka hijau dan tutupan vegatasi koefisien limpasan di Kawasan UNNES berubah menjadi sebesar 0,4263

(2) Dari sebanyak 28 Zona yanga ada di Kawasan UNNES, beberapa Zona memiliki debit yang cukup besar (diatas $1 \mathrm{~m} 3 / \mathrm{dt}$ ), Zona tersebut adalah : Zona AA, Zona U, Zona Q, Zona W, Zona D, Zona I, Zona P, Zona R, Zona F, dan Zona V

(3) Dari sebanyak 28 Zona yanga ada di Kawasan UNNES, beberapa Zona memiliki peningkatan debit yang cukup besar (diatas 100 persen) atau lebih 2 (dua) kali dari debit sebelum pengembangan, zona-zona tersebut adalah: Zona N, Zona W, Zona M, Zona I, Zona $\mathrm{P}$, Zona R, Zona Q, Zona B, Zona Z, Zona AB, Zona AA, Zona D, Zona F, Zona O, Zona J, Zona U, Zona H, Zona K, dan Zona C.

(4) Dari volume hujan yang masuk ke Embung UNNES sebesar $15.367 \mathrm{~m} 3$, sebesar 5.312 m3 (34,57\%) mampu ditampung Embung dengan asumsi sebelum hujan, embung dalam keadaan kosong.

(5) Untuk mengatasi peningkatan Debit puncak akibat pengembangan UNNES, maka dibangun sumur resapan dengan kedalaman 3 meter dan diameter $80 \mathrm{~cm}$ sebanyak 1.388 buah.

\section{DAFTAR PUSTAKA}

Chow V.T, Maidment D.R. and Mays L.W.. (1988). Applied Hydrology. McGraw-Hill Publishing Company

Haan. (1977). Statistical Methods in Hydrology. lowa: The lowa State Universities Press.

Istiarto. (2014). Analisis Frekuensi Data Hidrologi (AProb_4.1). http://istiarto.staff.ugm.ac.id/index.php/20 14/12/analisis-frekuensi-data-hidrologiaprob 4-1/

Sedyowati, L. dan Suhartanto, E. Kajian Pengaruh Sistem Drainase dan Ruang Terbuka Hijau Eksisting Pada Kawasan Ruas Jalan Utama Kota Malang (Suatu Upaya Pengendalian Genangan di Daerah Perkotaan), journal.umm.ac.id/index.php/jmts/article/v iew/2544

Sri Harto. ( 2000). Hidrologi. Yogyakarta: Nafiri Offset.

Sumiyadi. (2017). Analisis Dampak Perubahan Tataguna Lahan Sub DAS Beringin di Bukit Semarang Baru Terhadap Peningkatan Debit Sungai Beringin Kota Semarang. Jurnal Teknik Sipil dan Perencanaan, Vol 19 (1), Halaman 3138.

Sunjoto. (2009). Pembangunan Sumberdaya Air dalam Dimensi Hamemayu Hayuning Bawono. Yogyakarta : Hasta Cipta Mandiri

Suripin. (2004). Pengembangan Sistem Drainase yang Berkelanjutan, Yogyakarta : Andi Offset.

Triatmodjo.B. (2014). Hidrologi Terapan, Yogyakarta : Beta Offset

Upomo, T.C., Kusumawardani R. (2016). Pemilihan Distribusi Probabilitas Pada Analisa Hujan Dengan Metode Goodness Of Fit Test. Jurnal Teknik Sipil dan Perencanaan, Vol 18 (2), Halaman 139-148. 